\title{
Five decades in the study of natural products*
}

\author{
T R GOVINDACHARI ${ }^{\dagger}$ \\ Last address: 24, Crescent Park Street, T. Nagar, Chennai 600 017, India
}

\begin{abstract}
This paper describes the five-decade long fascinating journey taken by Prof. T R Govindachari towards the study of the natural products of India. A variety of Indian plants were investigated by him for the study of their constituent alkaloids and terpenoids. The concluding part of the paper summarizes the isolation and identification of the constituents of the Neem kernel, which eventually led to the first $\mathrm{X}$-ray structure determination of azadirachtin A.
\end{abstract}

Keywords. Natural products; tylophora alkaloids; carpaine; tiliacorine; ishwarone; azadirachtin A.

I thank the Chemical Research Society of India for awarding me a medal for Life Time Achievement and I accept it with grateful appreciation. My career in research has been contemporaneous with those of several luminous intellects in the second half of the twentieth century who have given a new direction to organic chemistry from the classical era of Robinson, Willstatter and others in the first half of the century. Organic Chemistry has been developing at a phenomenal pace during the last twenty years. It is against this backdrop that I was reluctant to give a lecture on this occasion. However, I shall now present a brief account of my career in research spread over a period of sixty years. Much to my dislike, I cannot avoid an autobiographical slant!

After passing the B Sc degree examination in 1934, I gave up a seat in the Madras Medical College to work for the M Sc degree by research under Prof B B Dey at Presidency College, Madras. Professor Dey was the leading organic chemist at that time in India and there was more research in Inorganic Chemistry and Physical Chemistry in Calcutta and other centres in North India. Prof Dey was largely interested in the chemistry of coumarins and of the opium alkaloid, narcotine. I was given a problem on the synthesis of the isoquinoline ring system by a new route. Nothing much came out of this but I got my degree, the examiners being Sir Robert Robinson and Sir Ian Heilbron. I had considerable difficulty in getting any fellowship and the jobs for M Sc's were also few. However, towards the end of 1938, Prof Dey gave me a Madras University Scholarship and later in early 1940 a research assistantship on a project funded by BSIR on the electrolytic reduction of nitrocompounds. The objective was to develop processes for (synthesis of) the dye intermediates benzidine and its analogues by the electrochemical route. I had little knowledge of the field. By dint of hard work, electrolytic

\footnotetext{
* Text of the lecture delivered by Prof T R Govindachari when accepting the Lifetime Achievement Award in January 2000 during the 2nd Natural Chemistry Symposium held at the Indian Institute of Chemical Technology, Hyderabad.

†Prof T R Govindachari passed away on 28 December 2001, shortly after he sent this paper to us.
} 
methods (of synthesis) were developed for benzidine, tolidine, dianisidine etc. A pilot plant for (making) benzidine on a $20 \mathrm{~kg}$ scale was also set up. During a visit to our laboratory, Prof K Venkataraman, Director of UDCT, Bombay was horrified to see me working with benzidines and advised me to stop working on such highly carcinogenic compounds. At present benzidines and dyes made from them are banned internationally. The War ended in 1945 and I was still working on the BSIR project. The same year, Madras University introduced the $\mathrm{Ph} \mathrm{D}$ degree and some of us were permitted to submit theses, although we had not registered. I cobbled up a thesis using material from the work on the project and in due course I was awarded a Ph D degree. If I had continued I would have probably ended up at CECRI, Karaikudi, set up in 1953, as a scientist.

Early in 1946, Sir Malcolm Sargent, Educational Adviser to the Government of India (British) brought a proposal to send some 2000 Indian students to UK and USA for advanced studies using the money received by India for supply of wheat to the Allies during World War II. I was one among the 2000 to be selected. Some 500 of us were loaded on to a chartered freighter that sailed from Calcutta to reach San Francisco in 27 days. There Mr M S Sundaram, Educational Attache to the Indian Consulate received us and despatched us to various universities. I was sent to the University of Illinois at Urbana, Illinois without my asking for it. The University of Illinois has always been a top-ranking university in the USA and the Chemistry Department had Prof Roger Adams as its Head and he asked me to work with him. I was sent to study dyestuff chemistry and to fulfil this requirement he asked me to synthesise some pyridone dyes. Some thirty dyes were made and sent to Dupont for testing, but nothing exciting was found. That was the end of my dyestuff chemistry. Prof Adams then asked me to synthesise 2,5-dihydropyridine (not reported at that time) to confirm the structure of leucenol, a pyridone alkaloid and this I could do in a short time. After this Prof. Adams came one day into my laboratory with a bottle containing half a kilogram of a colourless crystalline substance labelled 'longilobine'. This alkaloid was originally isolated by RHF Manske in Canada from Senecio longilobus. After repeated crystallisation it had showed the same melting point and specific rotation but no reasonable molecular formula could be derived from the $\mathrm{C}, \mathrm{H}$ analysis. It could be a mixture of two or more substances. Chromatography which had been extensively used for coloured substances like carotenoids had rarely been used for colourless substances. TLC was unknown at that time and was to become a common laboratory technique only around 1959. Only basic alumina was available which could be modified to neutral and acidic alumina. Silica gel had not been introduced. However, I ventured on the separation by chromatography of the mixture of alkaloids, by the simple expedient of collecting a few drops of the eluant at periodic time or volume intervals on a watch glass, blowing off the solvent and seeing if there was any residue. If there was a break in the elution of material it meant there was a separation. By this procedure I could separate two alkaloids seneciphylline (1) and retrosine (2) from the mixture. These were called at that time $\alpha$ and $\beta$-longilobine ${ }^{1}$. Later, using a long column of $6^{\prime}$ length (1" dia). I was able to get two more alkaloids senecionine (3) and riddelline (4) which were less abundant. A number of alkaloids available in Prof. Adams laboratory isolated from S. Douglasii, carthamoides, eremophilus, ampullaceus and parksii were all shown to be mixtures of the same four alkaloids in varying amounts ${ }^{2}$. Each of these alkaloids had a characteristic band in the fingerprint region of the IR spectrum from which its presence or absence could be deduced. Some years later Culvenor ${ }^{3}$ and his associates carried out the separation of some pyrrolizidine alkaloids by partition 
chromatography using buffered glass powder and claimed better and easier separation of the alkaloids.



Seneciphylline

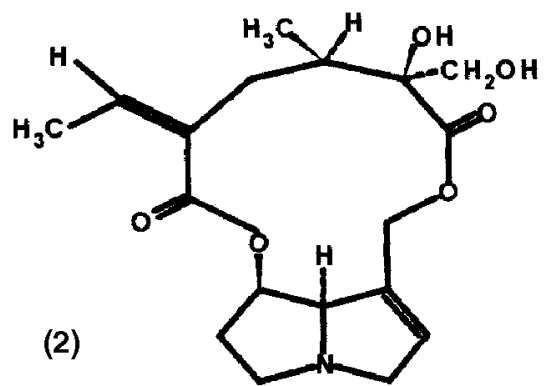

Retrosine<smiles></smiles>

Senecionine

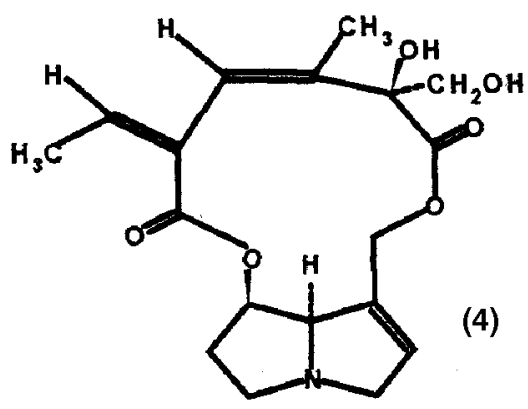

Riddelline

The structure of monocrotalic acid (5), the necic acid from monocrotaline, was difficult to prove since it easily decomposed to 2,3-dimethyl laevulinic acid on alkali treatment and at least three structures could be written. Prof Adams asked me to see if reduction with LAH could provide any clue. LAH had been reported by Nystrom and Brown ${ }^{4}$ only in 1948 and it had been shown that it could reduce $\gamma$-valerolactone in high yield to 1,4pentanediol. It occurred to me that the methyl ester should be used and not the acid itself. Methyl monocrotalate gave a quantitative yield of a tetrol, which consumed two mole equivalents of sodium metaperiodate to yield formaldehyde, acetic acid and $\beta$-methyl- $\gamma$ ketobutanol. From these results the structure of monocrotalic acid could be easily derived ${ }^{5}$.

Since monocrotaline (6) is a dilactone, the open form of the lactonic acid should be involved in dilactone formation with retronecine.

Prof Adams treated me with utmost consideration and affection. He gave me the opportunity of learning the fundamentals of the chemistry of natural products. My knowledge of organic chemistry was meagre, but at Urbana I could learn a great deal by sitting in all the courses offered in the department, which had an excellent faculty with Professors C S Marvel, R C Fuson, H R Snyder and N J Leonard, apart from Prof Adams in the Organic Chemistry section. 




I returned to Madras in October 1949 and thanks to Dr D S Reddy, Director of Public Instruction, all rules were relaxed and I was appointed Additional Professor of Chemistry at Presidency College, Madras and became Chief Professor in 1952. I decided to follow the example of my professor and mentor, B B Dey, who had established an excellent tradition of research in the Chemistry Department. I decided to work on structure elucidation of plant constituents, since India is endowed with plant wealth and medicinal properties were claimed for many plants. First, we started on plants collected in Madras and its environs. Later, with the help of Prof B GL Swamy, a great botanist and a specialist in plant taxonomy, we collected over thirty species which had not been studied before from the forests near Trichur in Kerala.

Very early, we realised that we could not make any headway unless we had facilities for elemental analysis, since at that time this was the only guide apart from melting points and specific rotation for establishing the identity of compounds and their purity. In Dr S Selvavinayakam, we found the right person to create analytical facilities. Soon we had microanalysis and UV spectroscopy. Only in 1960 could we acquire an IR spectrometer. Even with these meagre facilities we could turn out good quality work, thanks to the intelligence, experimental skill and enthusiasm of my students, and a large number of papers were published. In 1963 I took over as Director at the Ciba Research Centre, Bombay. The CRC Laboratory had a 'state-of-the-art' laboratory (at that time). Here a small group of us worked on plant chemistry. We had plant collectors, first Mr Rao and later Mr Almeida who kept up a continuous supply of plant material, mostly collected from the Western Ghats in Maharashtra. Over a period of twenty-five years (1950-1975) first at Madras and later at Bombay we had the opportunity of working on a large number of plant metabolites of novel structural types not known earlier. I shall now give a very brief account of some of these studies. Mostly, I have presented only the coup de grace experiments which conclusively proved the structures.

\section{Tylophora alkaloids}

Ratnagiriswaran and Venkatachalam ${ }^{6}$ had isolated two alkaloids from the plant Tylophora asthmatica Wight et Arn (syn. Tylophora indica), belonging to the family Asclepiadaceae, tylophorine (7) and tylophorinine (8), $\mathrm{C}_{24} \mathrm{H}_{27} \mathrm{O}_{4} \mathrm{~N}$ and $\mathrm{C}_{23} \mathrm{H}_{27} \mathrm{O}_{4} \mathrm{~N}$ 
respectively, which were separated by fractional crystallisation of the mixed salts. We separated these alkaloids by chromatography on alumina ${ }^{7}$ and also isolated tylophorinidine ${ }^{8,12}(\mathbf{9})$, septicine and isotylocrebrine ${ }^{9}$.<smiles>CCN1Cc2c(c3cc(OC)c(OC)cc3c3cc(OC)c(OC)cc23)CC1C</smiles>

Tylophorine<smiles>COc1ccc2c3c(c4cc(OC)c(OC)cc4c2c1)CN1CCC[C@H]1[C@H]3O</smiles>

Tylophorinine<smiles>COc1ccc2c(c1)c1c(c3ccc(OC)cc32)[C@H](O)[C@@H]2CCCN2C1</smiles>

Tylophorinidine

The crucial experiments which settled the structure of tylophorine were through three successive Hofmann degradations yielding a nitrogen-free compound $\mathrm{C}_{24} \mathrm{H}_{24} \mathrm{O}_{4}$ proving that the nitrogen was common to two rings. Oxidation of the second-stage Hofmann degradation product of tylophorine gave 2,3,6,7-tetramethoxyphenanthrene-9,10-dicarboxylimide.

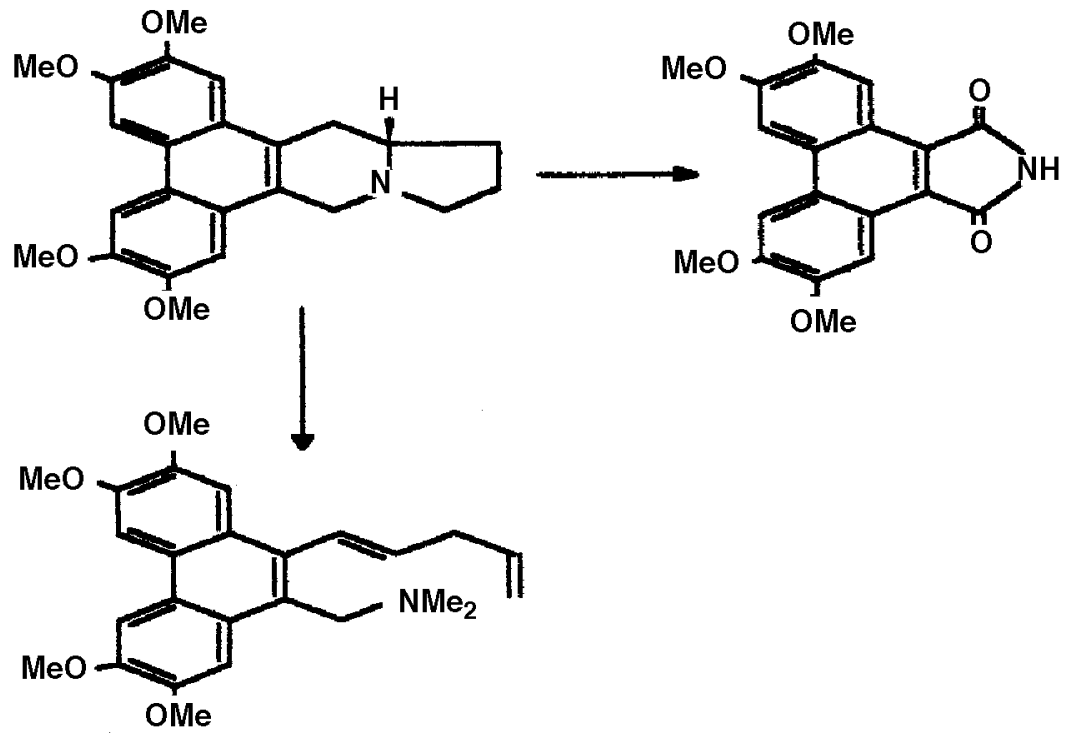

The structure was confirmed by a simple and straightforward synthesis ${ }^{10}$. Because of its anti-cancer activity, several syntheses have been carried out in other laboratories, three of them enantiospecific for the $R$ and $S$ enantiomers of tylophorine. We had earlier derived an $S$-configuration for the C-13a centre differing from these reports. Our results could have been due to a mix-up of samples. In the event, by use of a chiral column we found tylophorine was not enantiomerically pure but a mixture of the laevo and dextrorotatory forms in the proportion 60:40. Apart from tylophorine, we also solved the structures of tylophorinine ${ }^{11}$ and tylophorinidine ${ }^{12}$. The structure and absolute 


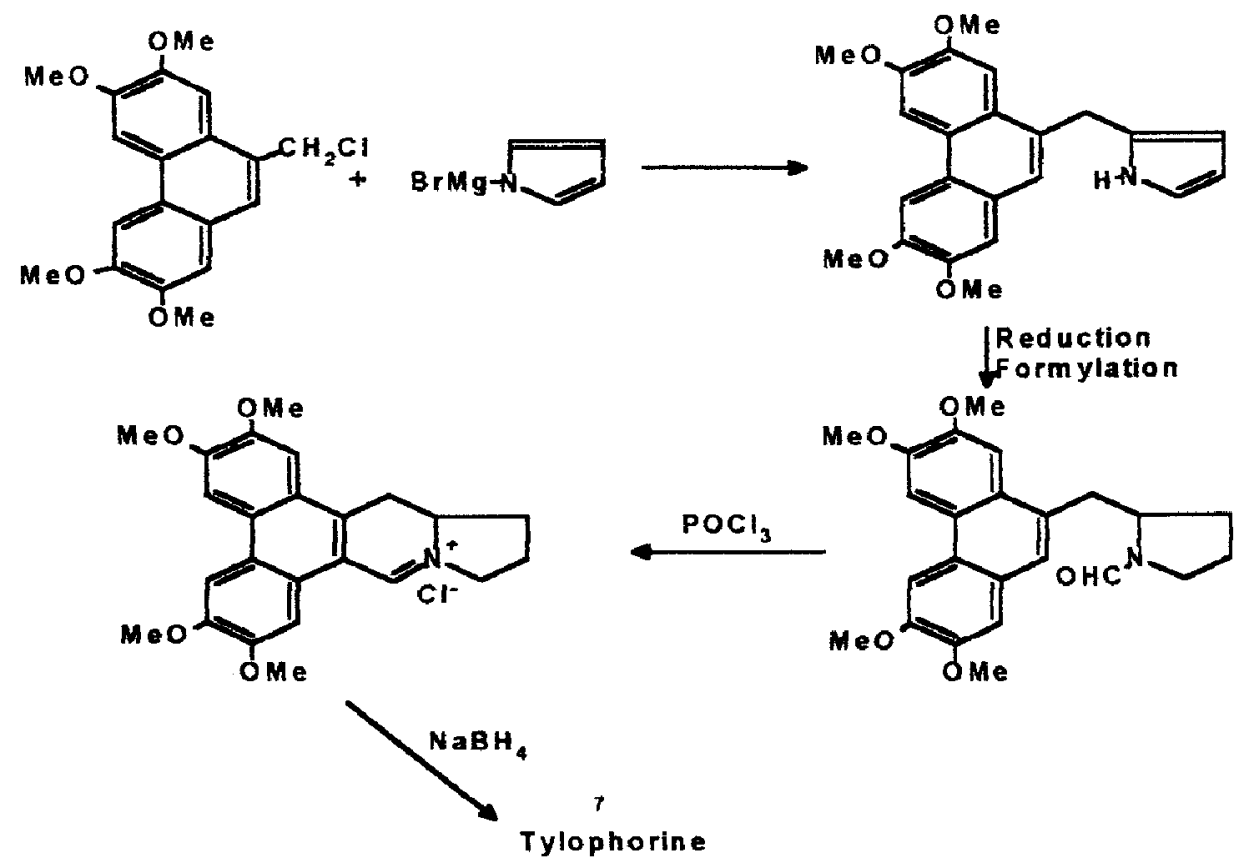

configuration of tylophorinidine has also been solved by X-ray studies ${ }^{13}$. Our work on the phenanthroindolizidine alkaloids has been extensive and our contributions have been summarised in review articles ${ }^{14}$.

\section{Carpaine}

The alkaloid carpaine from the leaves of Carica papaya was isolated in 1890 by Greshoff ${ }^{15}$. Barget et $a l^{16}$ assigned a pyrrolidine structure with a lactone moiety attached to the $\alpha$ position. Rapoport and Baldridge obtained by $\mathrm{Pd} / \mathrm{C}$ dehydrogenation of carpaine desoxycarpyrinic acid, a pyridine derivative in which a hydroxyl group had been cleaved during dehydrogenation ${ }^{17}$. By dehydrogenation of methyl carpamate, we obtained a pyridine compound with a phenolic hydroxyl group which was named carpyrinic acid ${ }^{18}$. Hence carpaine was a piperidine and not a pyrrolidine alkaloid. By extensive studies by us as well as in other laboratories, it was shown that the methyl group was at the 2-position, the octanoic acid side chain at the 6-position ${ }^{19}$ and the hydroxyl was at the 3position $^{20}$ and all the substituents on the piperidine ring were cis $^{21}$. A monolactone structure was proposed.

Some years later mass spectrometry showed that the molecular weight was 478 and therefore the structure should be revised to that of a dilactone ${ }^{22}(\mathbf{1 0})$.

We also isolated another minor alkaloid named $\psi$-carpane in our laboratory which yielded equal amounts of carpamic acid and an isomeric acid $\psi$-carpamic acid. Later we could show by study of $\psi$-carpaine by NMR that it differed from carpaine in that the configuration at the 2-position in one half was $R$ instead of $S$ as in carpaine. These alkaloids are diastereoisomers ${ }^{23}$. 


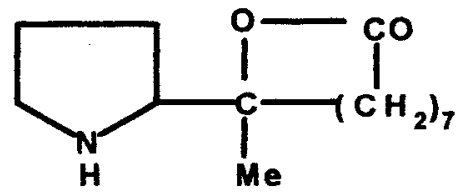

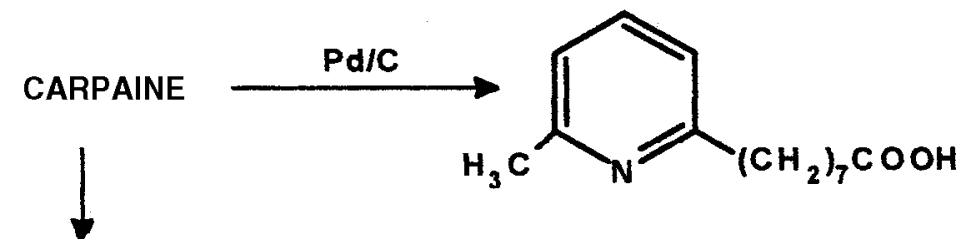<smiles></smiles>

Methyl carpamate<smiles>C[C@H]1N[C@H](CCC(=O)O)CC[C@H]1O</smiles>

Methyl carpyrinate<smiles>C[C@@H]1N[C@H](C)CC[C@H]1C</smiles>

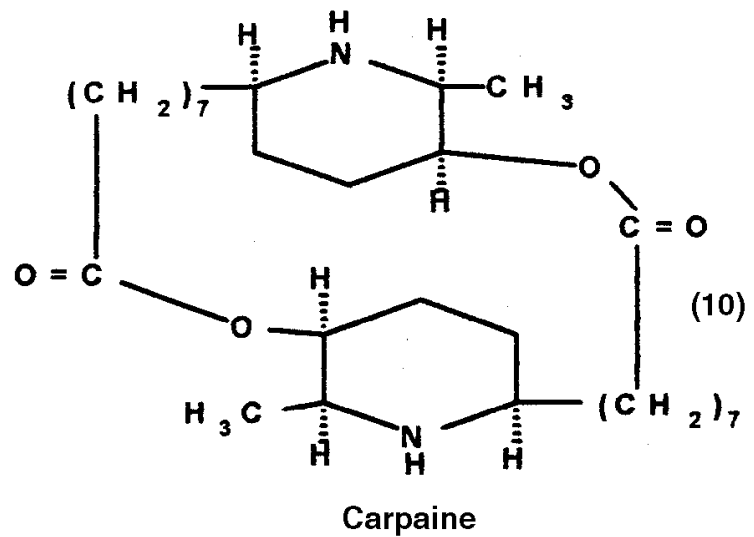

What revived our interest recently in carpaine is that it is a compound with a 26membered ring. Such large rings are not common among plant metabolites. There is a 

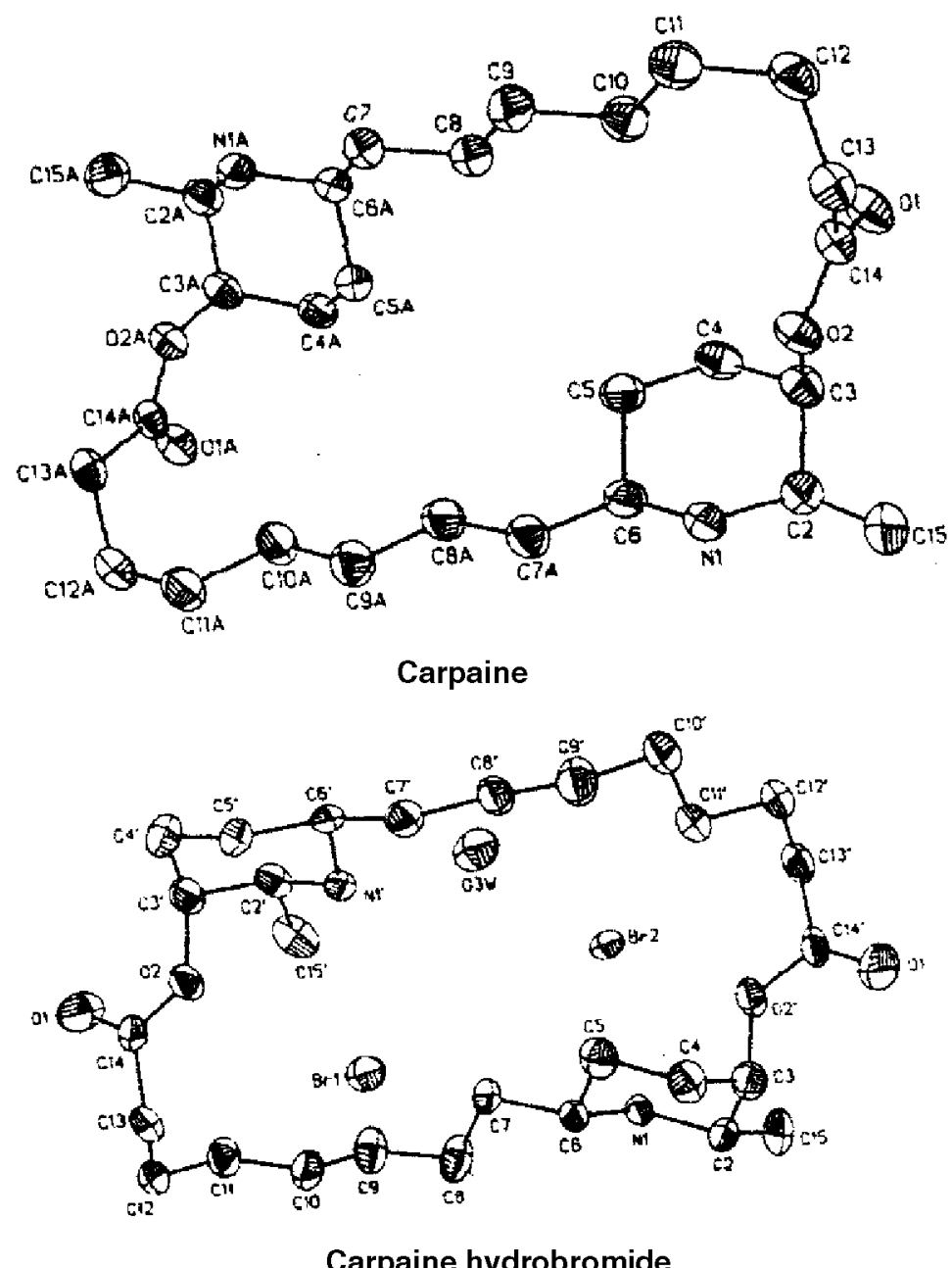

great deal of interest in such large rings with respect to host-guest chemistry. Prof S S Rajan carried out an X-ray study on carpaine and its dihydrobromide. The absolute configuration was confirmed as $2 S, 3 S, 6 R$ as indicated earlier by degradation studies ${ }^{24}$. Also in the hydrobromide there are two bromine atoms and a water molecule in the cavity and these atoms participate in hydrogen bonding with the two ring nitrogens.

It was shown that carpaine is not a rigid molecule and its conformation may change depending on the nature of the guest molecule ${ }^{25}$.

\section{Tiliacorine}

Tiliacorine (11), the principal alkaloid from Tiliacora racemosa Colebr. was unusual among bisbenzylisoquioline alkaloids in not only having a dibenzodioxin system but also having the two benzyl groups linked directly and not through an ether linkage as is common. 


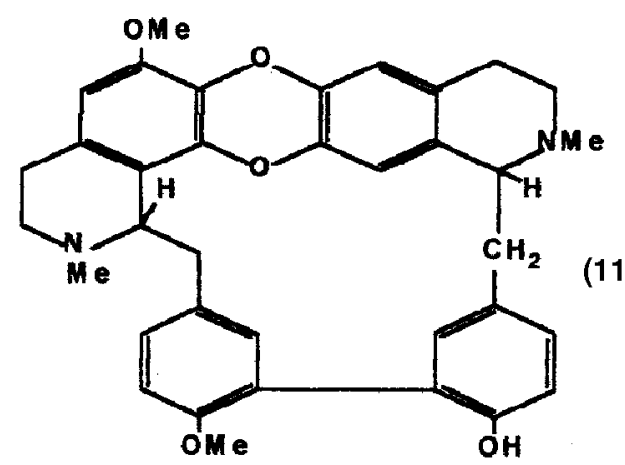

Tiliacorine

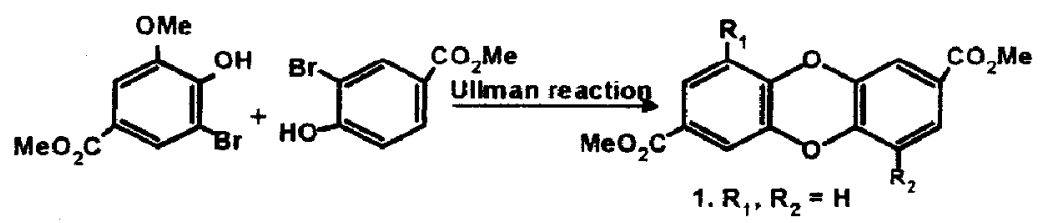

1. $R_{1}, R_{2}=H$

2. $R_{1}, R_{2}=O M e$

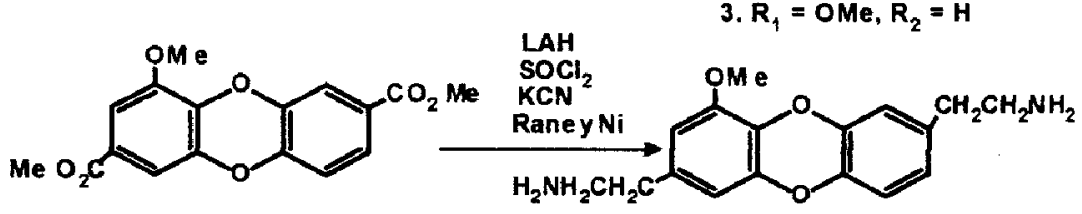

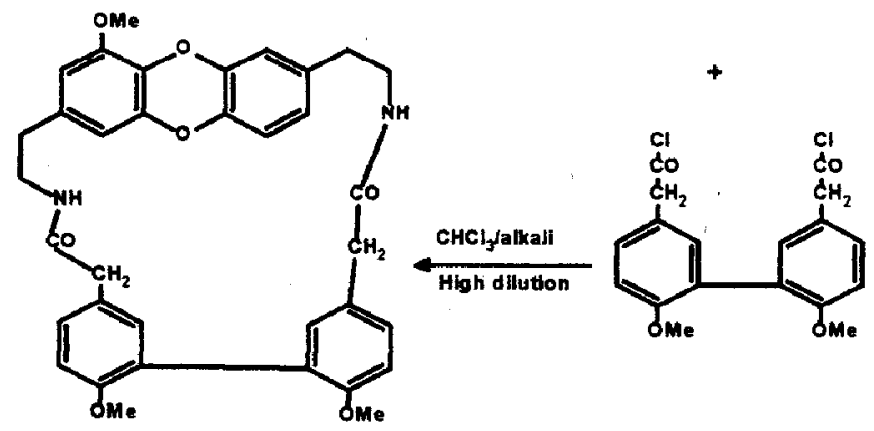




It is cryptophenolic and retains solvents tenaciously so that special methods had to be devised to obtain its methyl ether, after which its molecular formula could be worked out. The structure was elucidated mainly by oxidation methods ${ }^{26}$. The synthesis of O-methyltiliacorine was achieved by standard, but very demanding, experimental steps ${ }^{27}$.

Bhakuni et $a l^{28}$ determined the absolute configuration by a novel biosynthetic route, by which it was established that tiliacorine has $S$ and $R$ configurations at C-1 and C-1', while the minor alkaloid tiliacorininine has $S S$ configurations at both centres.

\section{Ancistrocladine and its congeners}

The value of random examination of plants was reaffirmed by the isolation of the alkaloids ancistrocladine (12), ancistrocladinine (13), ancistrocladisine (14) and ancistrocladidine (15) from Ancistrocladus heyneanus Wall, the only species of the family Ancistrocladaceae occurring in India ${ }^{29,30}$.

(12)

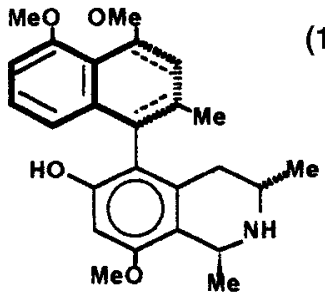

Ancistrocladine
(13)



Ancistrocladinine
(16)

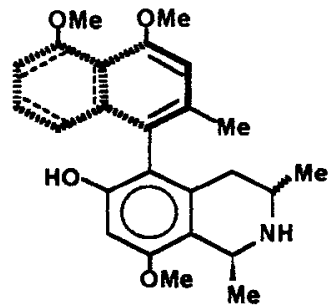

Hamatine

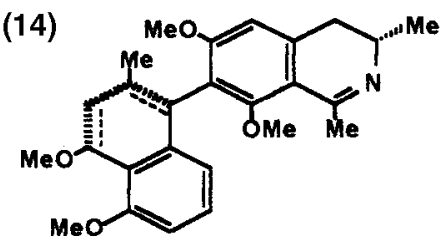

Ancistrocladisine

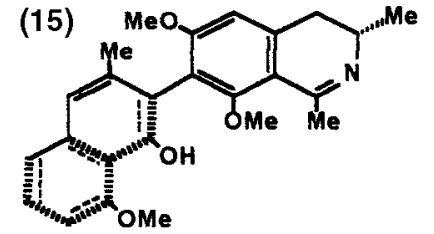

Ancistrocladidine

These represent a totally new class of alkaloids to be reported in the last fifty years. The structures were established by extensive degradation studies and the liberal use of NMR data. These alkaloids are unique in having a methyl group at C-3 in the isoquinoline ring. All these alkaloids have a $3 S$ configuration. An X-ray study carried out by the late Prof $G$ Kartha showed that the isoquinoline and the naphthalene rings were at an angle of $87^{\circ}$. The 3-methyl group and $2^{\prime}$-methyl group were on the same side of the plane of the isoquinoline ring and the 1-methyl group in ancistrocladine was below the plane. Putting these data together one could deduce the absolute configuration even with regard to the axial asymmetry. We applied the exciton chirality method with the help of Prof Nakanishi and found a first negative Cotton effect which confirmed that the chirality around the long axis is negative confirming the absolute configuration derived by a combination of the X-ray results with the absolute configuration derived for C-3 by the isolation of $S$ - $\beta$-amino- $n$-butyric acid by ozonolysis of ancistrocladine. The absolute configuration could be depicted as $1 S, 3 S$ and $5 P^{30}$. 


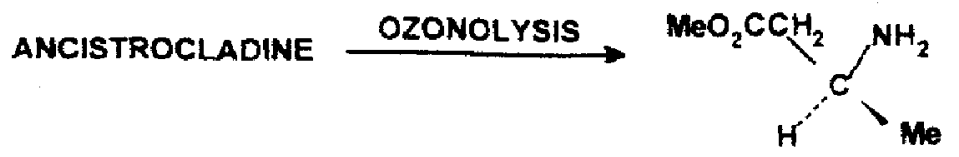

Methyl-(+)-L- $\beta$-amino-n-butyrate

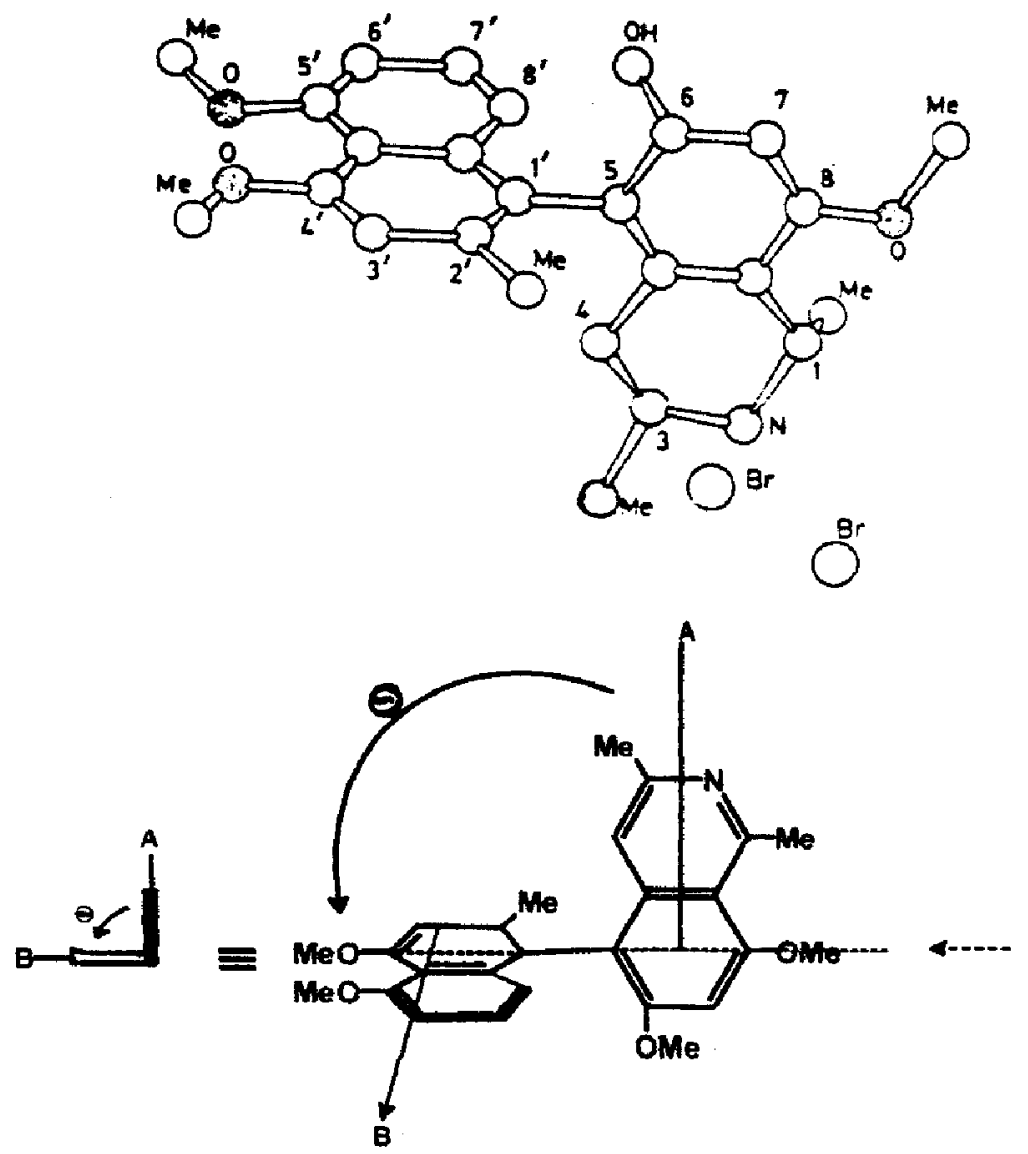

It was interesting that hamatine (16) isolated from Ancistrocladus hamatus had the same absolute configuration ${ }^{30}$ at $\mathrm{C}-1$ and $\mathrm{C}-3$ but the chirality along the long axis was positive and hence it was an atropoisomer of ancistrocladine, with the axial asymmetry being $5 M^{31}$.

We isolated only five naphthylisoquinoline alkaloids but later Prof G Bringhmann has expanded this field by working on other species of Ancistrocladaceae collected from Africa and the related family Dioncophyllaceae. He has isolated more than fifty-five alkaloids of the naphthylisoquinoline type and characterised them in all aspects, structure, stereochemistry and synthesis. In an African species A. korupensis even the dimers of these alkaloids like michellamine have been isolated and characterised ${ }^{32}$. 


\section{Alkaloids of Nothapodytes nimmoniana}

The value of random examination of plants was proved by the isolation of camptothecin (17a) from Nothopodytes nimmoniana (Graham) Mabberley, originally named Mappia foetida Miers in an yield of nearly $0.1 \%$ from the wood of the tree and also 9-methoxycamptothecin $^{33}$ (17b) and mappicine ${ }^{34}$ (18). Campthotheca accuminata yields only $0.005 \%$ of the alkaloid. Camptothecin and some modified compounds derived from it are used in cancer chemotherapy.

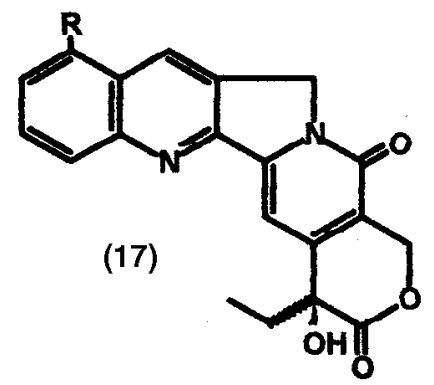

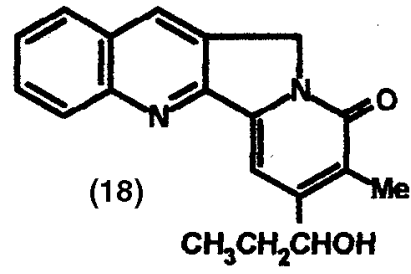

Mappicine

a. $\mathrm{R}=\mathrm{H} \quad$ Camptothecin

b. $\mathrm{R}=\mathrm{OMe}$ 9-Methoxy camptothecin

We have worked on the elucidation of structure of perhaps ten more alkaloids and the synthesis of over twenty alkaloids belonging to the aporphine, berberine, furoquinoline groups.

I will now turn to the work on terpenoid compounds in which our group made important contributions by describing a few cases.

\section{Ishwarone}

The sesquiterpene ishwarone (19) was first isolated by Prof B L Manjunath at Central College, Bangalore from Aristolochia indica Linn. called ishwaramuli in Kannada ${ }^{35}$. It proved to belong to the rare class of tetracyclic sesquiterpenes. The elucidation of its structure took a long time with dozens of experiments which have been summarised in a comprehensive paper ${ }^{36}$. During the latter half of this study we had access to a $100 \mathrm{MHz}$ spectrometer of which ample use was made. I shall only indicate the crucial experiment which settled its structure and absolute configuration.

\section{Polyalthic acid}

From Polyalthia fragrans (BTH) was isolated a novel diterpenoid, the first of its kind incorporating a $\beta$-substituted furan ring. Extensive spectral and degradation studies indicated the features depicted in the structure shown (20). Final confirmation was obtained by oxidation experiments on polyalthic acid and on neoabietic acid of known structure and configuration ${ }^{37}$.

We obtained two isomeric acids which were nearly identical in melting points and specific rotations except that the signs of rotation were opposite. These two acids are enantiomeric. 
(19)<smiles>CC1CCC(=O)C23CC4CC(C)(C2)C(C)(C4)C13C</smiles>

Ishwarone<smiles>CC(C)C1CC[C@H]2C(=O)CC[C@@H](C)[C@]2(C)C1</smiles>

(+) Nootkatane
1. $\mathrm{HCl}$

2. Pyridine

3. Ketalisation

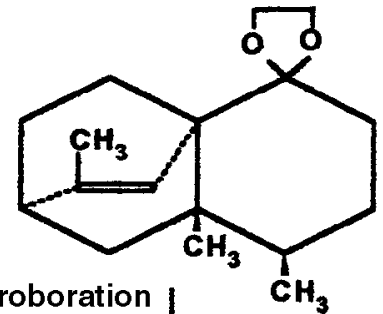

1. Hydroboration

2. $\mathrm{H}_{2} \mathrm{O}_{2} / \mathrm{NaOH}$

3. Deketalisation

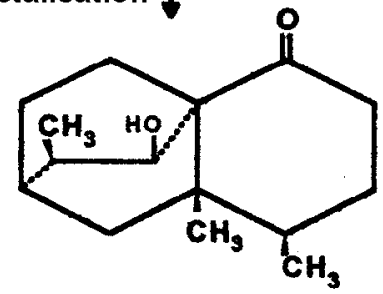

\section{Retro Aldol}

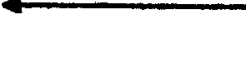

micarbazone

Wolff-Kishner<smiles></smiles>

Polyalthic acid



Neoabietic acid<smiles>C=C(C)C1CC[C@@H]2CCCC(C)[C@@]2(C)C1</smiles>

Valencene<smiles>CC1(C(=O)O)CCC(=O)[C@H](CCC(=O)O)[C@@]12CCCC[C@]2(C)C(=O)O</smiles>

m.p. 212

$[\alpha]_{D}+11.6$

Lactone ester $[\alpha]+88.3$<smiles>CC1(C)CCC[C@]2(C)C(CCC(=O)O)C(=O)CC[C@]12C(=O)O</smiles>

m.p. 212

$[\alpha]_{D}-16.5$

Lactone ester $[\alpha]-80.6$ 


\section{Litsomentol}

A new tetracyclic triterpene, litsomentol was isolated from Litsea tomentosa Heyne (Family Lauraceae) with the molecular formula $\mathrm{C}_{30} \mathrm{H}_{52} \mathrm{O}_{2}$. Extensive degradation studies combined with mass spectrometric studies indicated the structure (21).

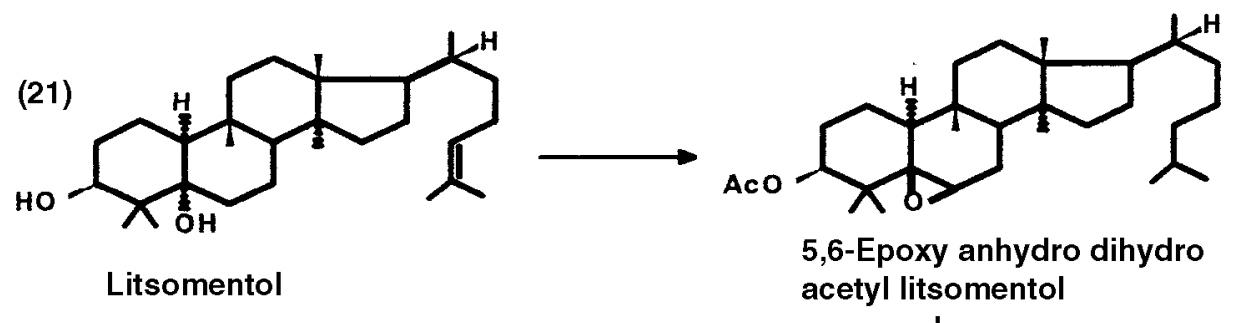

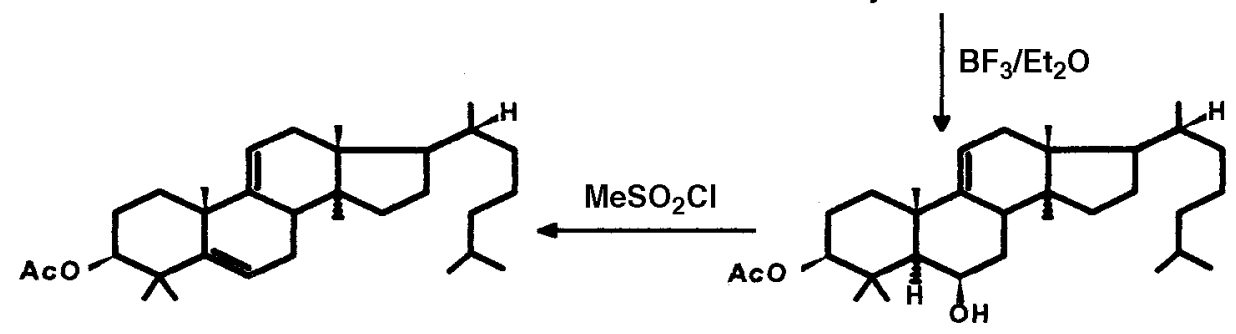

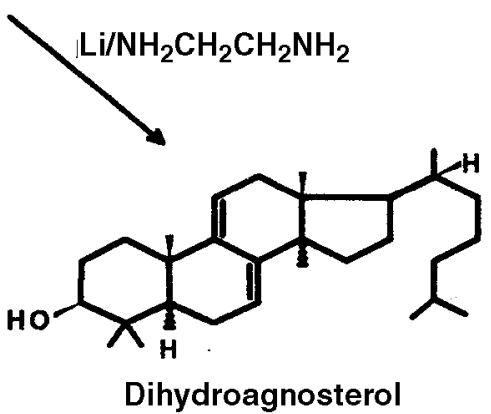

The unusual features are the presence of an $\propto-\mathrm{H}$ at $\mathrm{C}-10$ and an $\propto$ hydroxyl group at C-5. Cucurbitacins also have an $\alpha$-hydrogen at C-10 and a C-5-C-6 double bond. Perhaps the extreme toxicity of litsomentol may be due to this resemblance to cucurbitacins, toxic compounds isolated from the seeds of plants of Cucurbitaceae. The final solution to the structure of litsomentol (12) was obtained as shown in the sequence of reactions, which involves a backbone rearrangement with migration of the C-9 methyl group to C-10 with formation of a C-9-C-11 double bond. Our efforts to get the two double bonds into conjugation with a variety of bases did not succeed, but lithium in ethylenediamine did the trick and we could relate litsomentol ${ }^{38}$ to dihydroagnosterol, a component of sheep's wool fat of known structure and configuration.

\section{Wedelolactone}

We did considerable amount of work in the structural elucidation of a variety of oxygen heterocycles, on coumarins, flavanoids, lignans etc. I wish to speak here on wedelo- 
lactone B (22), which was one of our first essays into the chemistry of natural products. We had heard that Dr R Subramanyam, Dean of Madras Medical College administered a glass of the expressed juice of the leaves of Wedelia calendulacae Less (Asteraceae) to patients with liver disorders. Although it was one of the early problems tackled at Presidency College, I present it here since it also happened to be the first coumaranocoumarin to be reported in the literature ${ }^{39}$. This group has now been named coumestan. The key reactions for its structure elucidation are presented.

(22)<smiles></smiles>

Wedelolactone<smiles>COc1cc(OC)c(C(=O)Oc2cc(OC(C)(C)C)c(OC)cc2C=O)c(OC)c1</smiles>

The combined work carried out at Presidency College and Ciba Research Centre must have produced over two hundred papers.

In 1975, after returning to Madras, at the request of Dr M Santappa. I spent two years as Adviser at CLRI (Central Leather Research Institute, Chennai). Here there was more emphasis on synthetic tanning materials and less on discovering new sources of condensed tannins from plants. In 1978 one of my former students, Mr S Radhakrishna, MD of Amrutanjan Ltd asked me to set up an R\&D laboratory for his company and I quit CLRI to undertake this task. Enough funds were provided for equipment so that we could undertake good natural products chemistry. During the next eight years we were ready with laboratory scale processes for vinblastine, vincristine, ajmalicine, colchicine and some synthetic drugs. However, the management was not interested in making use of any of this know-how and I felt I was wasting my time and quit. Like Voltaire's Candide at the end of his tortuous life, I said to myself "We must cultivate our garden". However, in early 1987, in a chance meeting, Dr A C Muthiah, President, Southern Petrochemical Industries Corporation of India requested me to set up an R\&D laboratory for looking into problems related to agriculture. I readily agreed since I felt I could look after the garden in the mornings and spend the day in a laboratory. Enough funds were provided for setting up a good laboratory so that we were mostly self-sufficient. One of the greatest 
problems faced by agriculture is the depredation of crops by insects and pathogenic fungi. There is concern worldwide on the damage caused to the environment through the use of synthetic pesticides and fungicides which are generally toxic compounds.

\section{Chemistry of neem}

Our first aim in the new laboratory was to develop non-toxic pest control agents from the plant kingdom. The second was to develop more efficient procedures for the separation and purification of plant constituents instead of the age-old column chromatography. The neem tree has come into great prominence since Morgan's isolation ${ }^{40}$ from neem kernels of azadirachtin which is effective as an antifeedant and ecdysis inhibitor against several hundred insect species at ppm levels. The structure of azadirachtin (23) was established by a cooperative effort between several laboratories and took seventeen years using mainly NMR spectroscopy ${ }^{41}$.

The remarkable biological activity of azadirachtin led to the chemical examination of all parts of the neem tree and a large number of triterpenoid compounds were isolated using column chromatography and structures were assigned using NMR data ${ }^{42}$. We could show that the principal compounds of neem could be separated effectively by preparative hplc as shown ${ }^{43}$ (figure 1).

We could also prepare azadirachtin in $98 \%$ purity ${ }^{44}$ (figure 2) and succeeded in crystallising it for the first time ${ }^{45}$.

Prof S S Rajan (Biophysics Dept., Madras University) determined its structure by X-ray diffraction ${ }^{46}$ (figure 3 ).

Azadirachtin is a tetranortriterpneoid with a decalin segment and a modified furan segment which are joined by a single bond between C-8 and C-14. In our laboratory we have improved the isolation procedures for azadirachtin A (23) as well as B (24) and D (25) and also isolated new azadirachtins $\mathrm{H}^{47}$ (26), $\mathrm{I}^{47}$ (27) and $\mathrm{K}^{43}(\mathbf{2 8})$.

Other azadirachtin congeners have also been isolated and there are more than thirty compounds of this type ${ }^{48}$. The method can also be applied to other species of Meliaceae for isolating the major components in pure form in a short time ${ }^{49}$. All this work has gone hand in hand with assessment of these compounds for anti-feedant and growth regulation activity against insect pests and against plant pathogens. We are happy that we could contribute a little to the chemistry of neem and also develop ecofriendly means of insect

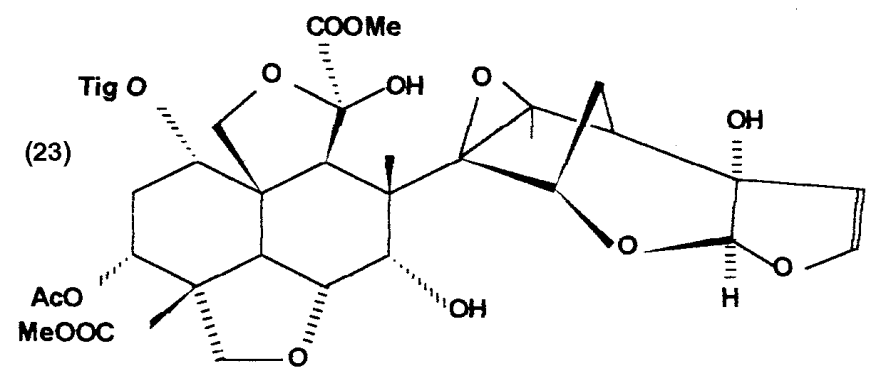

Azadirachtin A 




Figure 1. Chromatogram of neem kernel constituents (preparative RP-18 column, $25 \times 3 \mathrm{~cm} \mathrm{ID)}$.

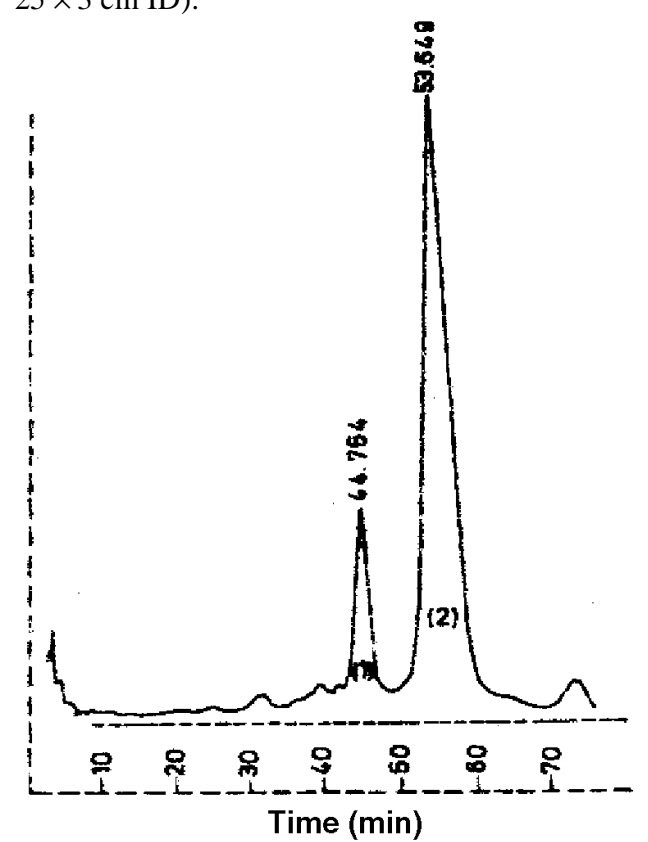

Figure 2. Chromatogram of azadirachtins $A$ and $D ; 1=$ azadirachtin $D, 2=$ azadirachtin A. 


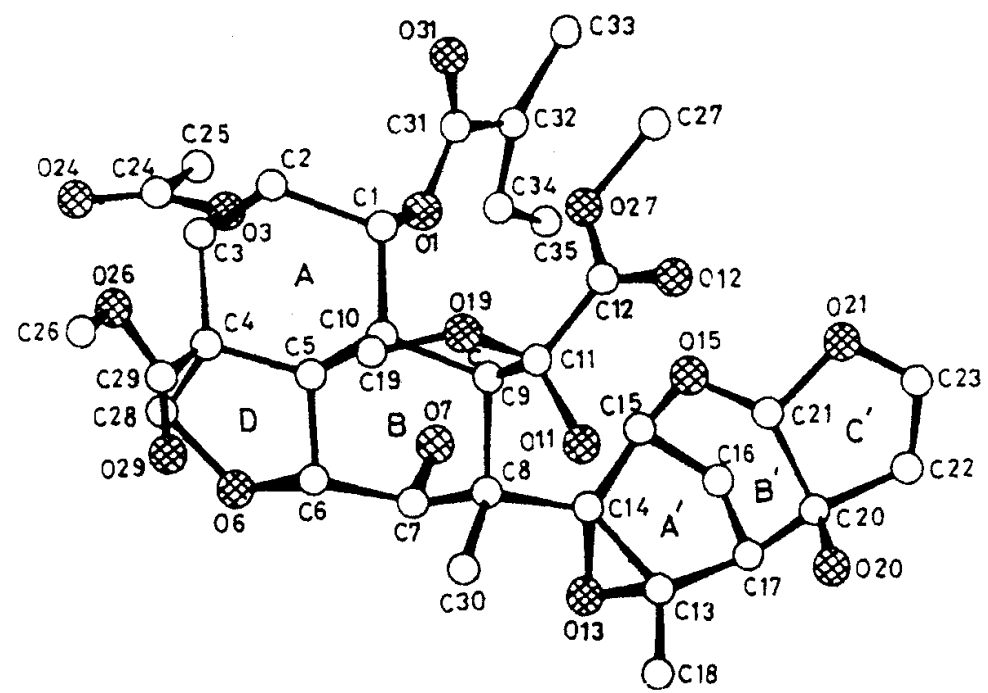

Figure 3. Structure of azadirachtin A, 23.
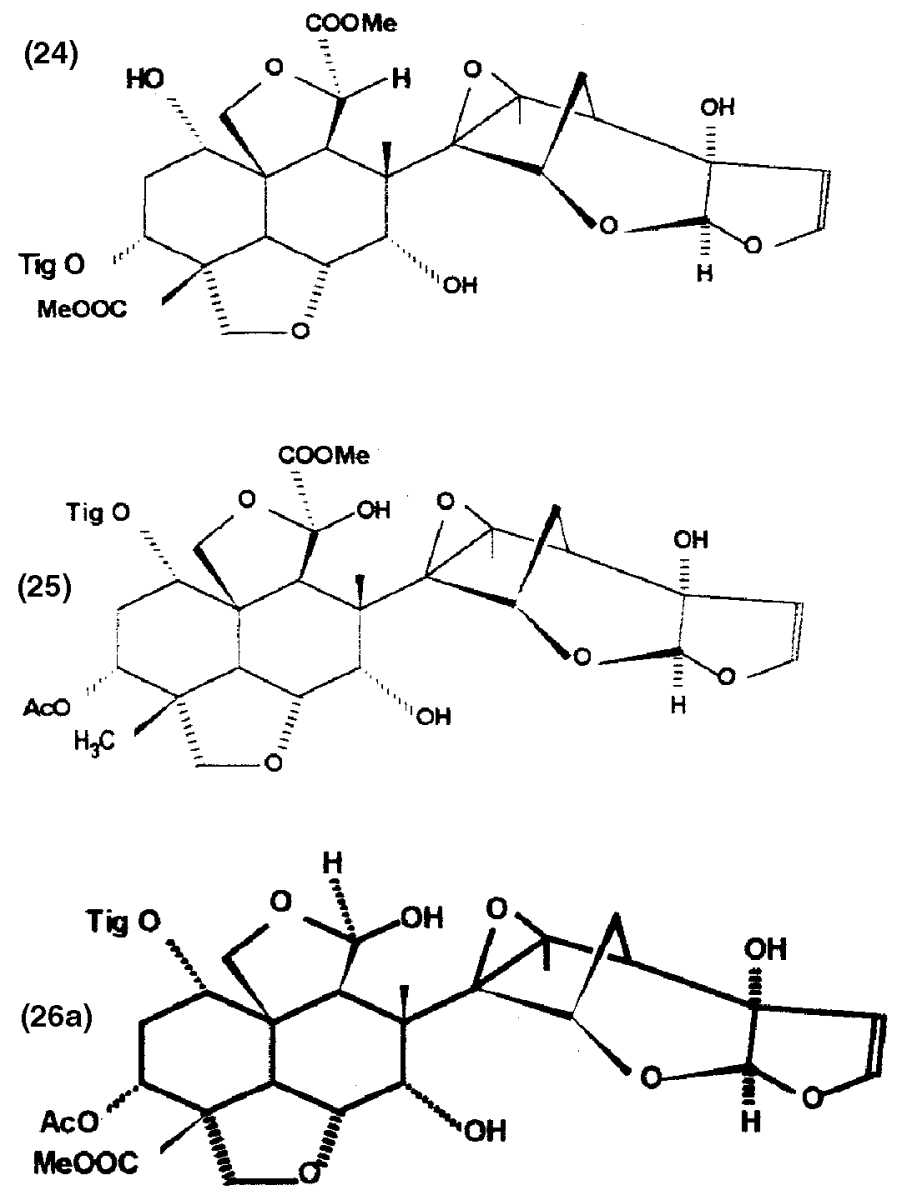


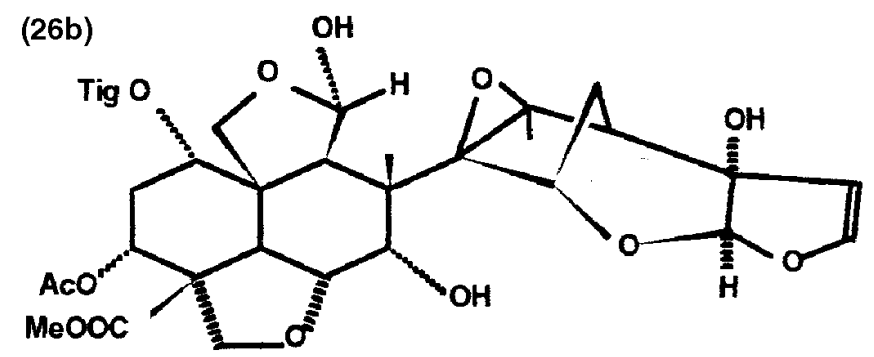



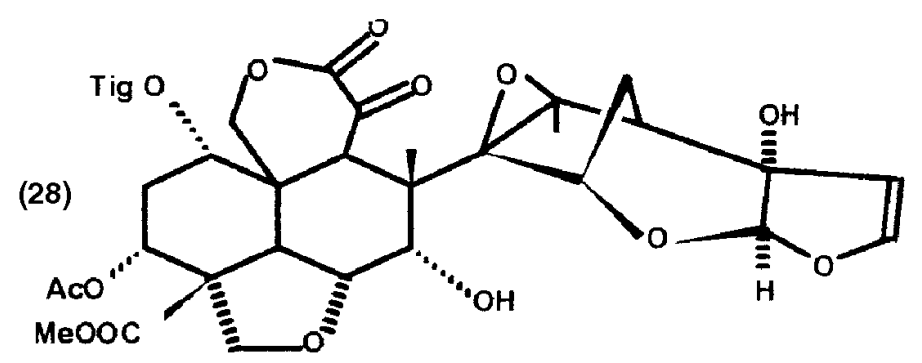

control. Investigation of natural products for insect and pathogen control are being actively pursued in our laboratory. Research in Natural Products is not glamorous to chemists of the present generation, but it is relevant and necessary to the needs of this country. In this faith we go on with our work.

\section{Acknowledgements}

I owe an immense debt of gratitude to my coworkers over the years, who were responsible for the research output. The late Professor B R Pai for his selfless and unstinted help in setting up a research laboratory at Presidency College. Dr K Nagarajan who has been associated with me for the last five decades directly or indirectly and with his wide knowledge and quick grasp of problems has been of inestimable help in my research career. Dr N S Narasimhan and Dr S Rajappa who tackled difficult problems in structure elucidation right at the beginning and set a high standard by their intellectual inputs and experimental skill. Dr N Viswanathan and Dr PC Parthasarathy for their prodigious output both at Presidency College and CIBA Research Centre, which contributed in ample measure to the quality and quantity of our research contributions. 
Drs M S Premila, S Chandrasekharan, S Natarajan and S Rajeswari who aided in process development at Amrutanjan Ltd and also carried out basic research in the chemistry of natural products. My present colleagues Drs G Suresh, G Gopalakrishnan and G N Krishna Kumari who have played a big part not only in structure elucidation of plant metabolites but also in examining their biological activities. To them as well as Miss A Radha for help in the preparation of this manuscript. To CSIR for support in my student days and later during my years at Presidency College. To DBT for generous funding of our research activities in SPIC Science Foundation. Finally to Mr S Radhakrishna and Dr A C Muthiah who made it possible for me to continue as a research scientist long after my retirement in 1975 .

\section{Editor's note}

This paper contains the text of the lecture delivered by Prof T R Govindachari on 28-29 January 2000 at the Chemical Research Society of India Meeting in Hyderabad, when the Lifetime Achievement Award was conferred on him. The manuscript is virtually unedited to retain the flavour and passion with which the lecture was delivered. The Editorial Committee felt that this publication would provide readers a glimpse of a great mind elucidating the fine art of organic synthesis and logical deduction of organic structures. For those who were present at that time, it was a memorable experience listening to an illustrious organic chemist, expounding the agony and ecstasy of doing excellent organic synthesis! Each one of the structures listed in this publication has been a landmark of its time. Prof Govindachari is no more with us but his dedication and contribution to chemistry will remain a guiding spirit to the Chemical Fraternity.

\section{References}

1. Adams R and Govindachari T R 1949 J. Am. Chem. Soc. 711180

2. Adams R and Govindachari T R 1949 J. Am. Chem. Soc. 711956

3. Culvenor C C J et al 1954 Aust J. Chem. 7277

4. Nystrom R F and Brown W G 1948 J. Am. Chem. Soc. 703738

5. Adams R and Govindachari T R 1950 J. Am. Chem. Soc. 72158

6. Ratnagiriswaran A N and Venkatachalam K 1935 Indian J. Med. Res. 22433

7. Govindachari T R, Pai B R and Nagarajan K 1954 J. Chem. Soc. 2801

8. Mulchandani N B, Iyer S S and Badheka L P 1971 Chem. Ind. 505

9. Govindachari T R, Viswanathan N, Radhakrishnan J, Pai B R, Natarajan S and Subramanyan B S (unpublished results)

10. Govindachari T R, Lakshmikantham M V and Rajadurai S 1961 Tetrahedron 14284

11. Govindachari T R, Pai B R, Ragade I S, Rajappa S and Viswanathan N 1961 Tetrahedron 14 288

12. Govindachari T R, Viswanathan N and Pai B R 1974 Indian J. Chem. 12886

13. Wadhawan V K, Sikka S K and Mulchandani N B 1973 Tetrahedron Lett. 5091

14. Govindachari T R and Viswanathan N 1978 Heterocycles 11587

15. Greshoff, Mededeel, Uit's Lands 1890 Plant Buitenzorg 75

16. Barger G, Robinson R and Work J B 1937 J. Chem. Soc. 711

17. Rapoport H and Baldrige H D 1951 J. Am. Chem. Soc. 73 343; Rapoport H and Baldrige H D 1952 J. Am. Chem. Soc. 745365

18. Govindachari T R and Narasimhan N S 1953 J. Chem. Soc. 2635; Govindachari T R and Narasimhan N S 1955 J. Chem. Soc. 1563

19. Govindachari T R, Narasimhan N S and Rajadurai S 1957 J. Chem. Soc. 558; Govindachari T R, Narasimhan N S and Rajadurai S 1957 J. Chem. Soc. 560

20. Govindachari T R, Narasimhan N S and Rajadurai S 1957 J. Chem. Soc. 560 
21. Tichy M and Sicher J 1962 Tetrahedron Lett. 511

22. Spiteller-Friedmann M and Spiteller G 1964 Monatsh 951234

23. Govindachari T R, Nagarajan K and Viswanathan N 1965 Tetrahedron Lett. 241907

24. Coke J L and Rice S S Jr 1965 J. Org. Chem. 303420

25. Kabaleeswaran V, Rajan S S, Krishna Kumari G N and Govindachari T R 1999 Acta Crystallogr. C55 1935

26. Jagannatha K V and Ramachandra Rao L 1957 J. Sci. Indian Res. B16 156; Jagannatha K V and Ramachandra Rao L 1959 J. Sci. Indian Res. B18 247; Anjaneyulu B, Govindachari T R, Sathe S S, Viswanathan N, Gopinath K W and Pai B R 1969 Tetrahedron 25 3091, and the references cited therein

27. Anjaneyulu B, Govindachari T R and Viswanathan N 1971 Tetrahedron 27439

28. Bhakuni D S, Singh A N, Jain S and Kapil R S 1978 J. Chem. Soc., Chem. Commun. 226

29. Govindachari T R and Parthasarathy P C 1971 Tetrahedron 271013

30. Govindachari T R and Parthasarathy P C 1977 Heterocycles 7661

31. Govindachari T R, Parthasarathy P C, Desai H K and Sindane M T 1977 Indian J.Chem. B15 871

32. Bringmann G 1986 In The alkaloids (ed.) A Brossi (New York: Academic Press) vol. 29, p. 141; Bringmann G and Pokorni R 1995 In The alkaloids (New York: Academic Press) vol. 46, pp 127-271

33. Govindachari T R and Viswanathan N 1972 Phytochemistry 113529

34. Govindachari T R, Ravindranath K R and Viswanathan N 1974 J. Chem. Soc., Perkin. Trans I 1215

35. Rao U S K, Manjunath B L and Menon K N 1935 J. Indian Chem. Soc. 12494

36. Fuhrer $\mathrm{H}$ et al 1970 Tetrahedron 262371

37. Gopinath K W, Govindachari T R and Parthasarathy P C 1961 Helv. Chim. Acta 441040

38. Govindachari T R, Viswanathan N and Mohamed P A 1971 Tetrahedron 274991

39. Govindachari T R, Nagarajan K and Pai B R 1956 J. Chem. Soc. 629; Govindachari T R, Nagarajan K and Pai B R 1957 J. Chem. Soc. 545; Govindachari T R, Nagarajan K and Pai B R 1957 J. Chem. Soc. 548

40. Butterworth J H and Morgan E D 1968 J. Chem. Soc., Chem. Commun. 23

41. Turner C J et al 1987 Tetrahedron 43 2789; Bilton J N et al 1987 Tetrahedron 43 2805; Kraus W et al 1987 Tetrahedron $\mathbf{4 3} 2817$

42. Kraus W 1995 In The neem tree, Azadirachta indica, A. Juss and other meliaceous plants (ed.) H Schmutterer (Weinheim: VCH) p. 35

43. Govindachari T R, Sandhya G and Ganesh Raj S P 1992 Indian J. Chem. B31 295

44. Govindachari T R, Sandhya G and Ganesh Raj S P 1991 Chromatographia 31303

45. Govindachari T R, Gopalakrishnan G, Raghunathan R and Rajan S S 1994 Curr. Sci. 66295

46. Kabaleeswaran V, Rajan S S, Govindachari T R and Gopalakrishnan G 1994 Curr. Sci. 66362

47. Govindachari T R, Sandhya G and Ganesh Raj S P 1992 J. Natural Prod. 55596

48. Govindachari T R and Gopalakrishnan G 1998 J. Indian Chem. Soc. 75655

49. Govindachari T R, Krishna Kumari G N and Suresh G 1997 J. Liq. Chromatogr. Rel. Tech. 20/19 3189 